\title{
Piezometry of the Aquifer of the Continental Terminal in the Borehole Fields of Godomey and Ouedo for the Delimitation of the Protection Areas around Boreholes of Ouedo
}

\author{
Crépin Zevounou ${ }^{1}$, Abdoukarim Alassane ${ }^{2}$, Christophe Kaki ${ }^{2}$, Taofic Bacharou ${ }^{1}$, \\ Joanèle Koudemekpo ${ }^{1}$
}

${ }^{1}$ Civil Engineering (GC), Polytechnic School of Abomey-Calavi (EPAC/UAC), Abomey-Calavi, Republic of Benin ${ }^{2}$ Department of Earth Sciences, Faculty of Sciences and Technics (FAST/UAC), Abomey-Calavi, Republic of Benin Email: zevoun oucrepin@gmail.com, aalassane@yahoo.fr, kaki_christophe@yahoo.fr, epac.uac@epac.uac,kzednele92@yahoo.fr

How to cite this paper: Zevounou, C., Alassane, A., Kaki, C., Bacharou, T. and Koudemekpo, J. (2017) Piezometry of the Aquifer of the Continental Terminal in the Borehole Fields of Godomey and Ouedo for the Delimitation of the Protection Areas around Boreholes of Ouedo. Open Journal of Geology, 7, 1786-1800.

https://doi.org/10.4236/ojg.2017.712120

Received: August 31, 2017

Accepted: December 10, 2017

Published: December 13, 2017

Copyright $\odot 2017$ by authors and Scientific Research Publishing Inc. This work is licensed under the Creative Commons Attribution International License (CC BY 4.0).

http://creativecommons.org/licenses/by/4.0/

\begin{abstract}
Groundwater is naturally protected against pollution through its filter layer which is the soil. However, the development of human activities, including the use of chemicals, gradually reduces the purifying action of this layer. It is therefore essential to develop strategies for a better management of this precious resource. The general objective of this work is to establish the piezometry of the aquifer of the Continental Terminal in the borehole fields of Godomey and Ouedo to improve the delineation of protection perimeters around the boreholes of Ouedo. The study was conducted using three methods that were the FCR method, the infiltration method and the method of Krijgsman and Lobo-Ferreira. The exploitation of the piezometric map enabled to obtain the hydraulic gradient of $0.165 \%$. The radii of immediate protection's perimeters (PPI) range from $55.653 \mathrm{~m}$ to $99.755 \mathrm{~m}$. The retained close protection' perimeters (PPR) and remote protection's perimeters (PPE) have an ellipsoidal shape. Their upstream radii range from $220.72 \mathrm{~m}$ to $390 \mathrm{~m}$ for PPR and from $356.52 \mathrm{~m}$ to $659.52 \mathrm{~m}$ for PPE; the downstream radii range from 213.06 $\mathrm{m}$ to $387.25 \mathrm{~m}$ for PPR, and from $321.28 \mathrm{~m}$ to $603.97 \mathrm{~m}$ for PPE; the radii perpendicular to the flow direction to the right of each borehole vary from $212.58 \mathrm{~m}$ to $381.16 \mathrm{~m}$ for PPR, and from $336.11 \mathrm{~m}$ to $602.67 \mathrm{~m}$ for PPE. Probable risks identified for groundwater contamination in these protection areas are the discharge of domestic waste water, solid wastes and the use of chemical fertilizers and pesticides in farming practices.
\end{abstract}

\section{Keywords}

Groundwater, Anthropogenic Activities, Protection Perimeter, Piezometry 


\section{Introduction}

Anthropogenic activities today are the main sources of water pollution, both surface and underground. These activities most often involve the dumping of domestic sewage from septic tanks, the dumping of solid wastes into lost wells, and the intensive use of chemical fertilizers and pesticides in agricultural practices.

Groundwater is generally an excellent source of drinking water. The natural filter constituted by the geological materials most often produces a high-quality water, with in particular very low contents of microorganisms and other substances in suspension. The maintenance of this relative advantage, however, requires that measures be taken to sustainably maintain the quality of the source of supply. An essential step in protecting the groundwater captured by a structure is the estimated feeding area of this structure [1], that part of the territory on which the infiltrating water will end sooner or later at the collection point.

Groundwater constitutes a part of the exploitable water resources to supply the population. To preserve its quality, this resource must not be in contact with any source of nuisances such as pollutants, wastewater resulting from domestic activities and the storage of household waste [2]. It is therefore essential to establish protective perimeters for the collection structure of this groundwater.

\section{Presentation of the Study Area}

The township of Abomey-Calavi, located in the southern part of the Republic of Benin and the Atlantic Department, is bounded in the north by the township of Zè, in the south by the Atlantic Ocean, in the east by the townships of Sô-Ava and Cotonou, and in the west by the townships of Tori-Bossito and Ouidah. It covers a surface area of $539 \mathrm{~km}^{2}$ representing $0.48 \%$ of the national area of Benin [3]. It is mainly the home to two catchment areas, the Godomey and Ouedo catchment areas. Previous work carried out on the plateau of Alladataking into account this municipality made it possible to distinguish over the first 200 meters recognized a superficial horizon and three lower horizons presenting hydraulic interconnections. This means that any pollution of one of the aquifers can affect the others.

\section{Material and Methods}

\subsection{Material and Data}

The equipment used to carry out this study consists of the following devices:

- A Fischer Darex brand measuring tape 20.013 meters long to measure the curb of the well;

- A sound and electric piezometric probe with a total length of 200 meters to measure the water level in each of the large diameter wells.

During this study, we needed the porosity $n$ of the aquifer captured, the thickness b of the saturated layer in each borehole of the catchment area, the operating flow $Q$ of each borehole in the catchment area, the hydrauliccon- 
ductivity $K$ of the aquifer at each drilling of the catchment area, the annual recharge of the aquifer collected and the hydraulic gradient $i$ of the aquifer collected.

\subsection{Methodology}

\subsubsection{Piezometric Map: Definition and Realization}

Hydrogeological mapping of a sector may include piezometry, vertical infiltration recharge, vulnerability, areas of high potential for contamination and the recharge area of a catchment. A guide has been produced by the International Association of Hydrogeologists [4] on cartography applied to hydrogeology in general.

The piezometric map is an essential synthesis of the hydrogeological study. This map allows an analysis of the hydrodynamic behavior of the aquifer and gives the configuration of the aquifer. It is the cartographic representation of the surface of the open water body by equipotential curves. The equipotential curves are curves of equal piezometric level, also called isopiezes. The realization of this piezometric map is done in several stages which can be summarized in four points: The first step is to have the field data: static level and coordinates of the measurement points. Measurements at different points of the water table should be carried out, if possible, at the same time or within a very short period of time to avoid excessive fluctuation of the water table The second step consists of plotting on a map the location of each measurement point and its piezometric dimension, determined by the formula:

\section{Piezometric dimension $=$ ground - levelstatic}

The third step consists in choosing the equidistance of the card then. The last step is to draw the curves. The set of curves obtained represents the piezometric map of the study environment. This map allows to determine the direction of the groundwater's flow and to calculate the hydraulic gradient of the aquifer. Piezometer installation techniques have been designed primarily to estimate the extent of a plume of contamination [5] [6]. However, we have not identified any work to date on an approach of this kind applied to the estimation of the groundwater catchment well supply area.

\subsubsection{Methods Used to Determine Protection Perimeters}

\section{- Calculated Fixed Radius Method (CFR)}

The radius to be fixed is calculated on the basis of a simple two-dimensional static water balance analysis, assuming the initial horizontal hydraulic load. Assuming a radial flow to a well in a horizontal bedrock aquifer of constant saturated thickness, the cylindrical catch limit is delineated by an isochrones of residence time $t$. The water balance for period $t$ is:

$$
Q t=N \pi R^{2} t+n \pi R^{2} H
$$

$H$ : initial saturated thickness of the aquifer. It is also called " $b$ ";

$R$ : is the capture radius for the given time $t$, 
$N$ : superficial recharge;

$n$ : effective porosity of the aquifer;

$Q$ : pumping rate;

The radius $R$ is expressed as follows:

$$
R=\sqrt{\frac{Q t}{N \pi t+n \pi H}}
$$

Figure 1 below shows the Water equilibrium of a radial flow for a well in an area delimited by anisochron of residence time (according to [7]).

When $t$ becomes infinitely large, the radius $R$ represents the complete capture zone (independent of time).

$$
R=\sqrt{\frac{Q}{\pi N}}
$$

This approach is called the recharge approach.

If the term $N \pi t$ becomes small because $t$ becomes small or $N$ or both, the equation become:

$$
R=\sqrt{\frac{Q t}{n \pi H}}
$$

This approach is called a volumetric approach.

Since the transfer times used for the calculations are not infinite (50 days, 2 years and 5 years), we will then use formula (4) for the determination of the PDP radii by the CFR method.

\section{- Vertical infiltration recharges method or infiltration method}

The infiltration method consists in establishing a mass balance between the volume of water taken per year and the volume of the annual average recharge in the catchment area of the catchment to be protected. The recharge can be evaluated from Darcy's law:

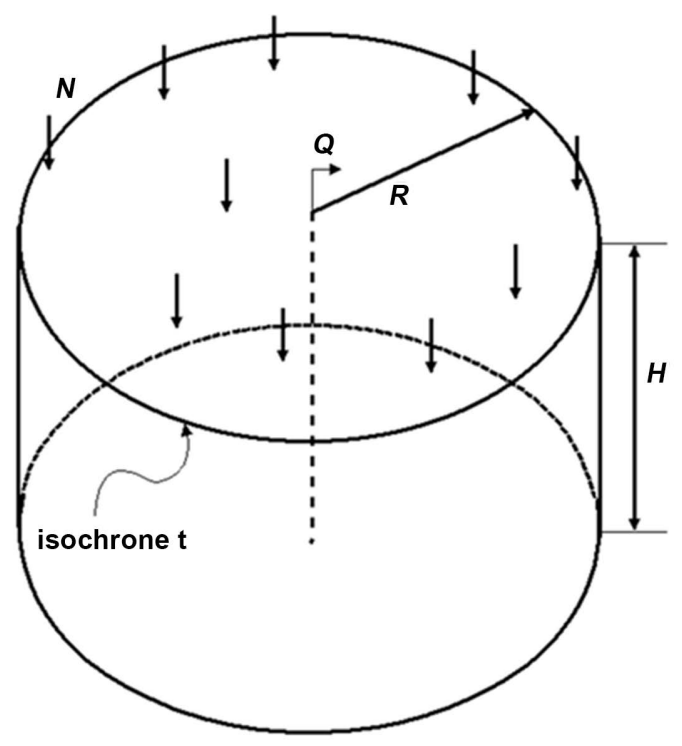

Figure 1. Water equilibrium of a radial flow. 


$$
W=\frac{K}{b} \Delta h
$$

where $\Delta h$ is the difference between the hydraulic load of the aquifer and that measured at the roof of the aquitard. Le ratio $\mathrm{K} / \mathrm{b}$ may be obtain by the interpretation of a pumping test in the aquifer, for example by Walton's technique [8]. The formula giving the radius of the zone to be protected is:

$$
R=\sqrt{\frac{Q}{\pi W}}
$$

$R$ : radius of the recharge area of the sheet, radius of the area to be protected (m);

$Q$ : flow through the vertical section of the sheet $\left(\mathrm{m}^{3} /\right.$ year);

$W$ : recharge of the water table (m/year)

\subsubsection{Method of Krijgsman and Lobo-Ferreira}

To determine the protection perimeters, Krijgsman and Lobo-Ferreiraleftan analytic relation found in the US EPA Guide. his relation was developed by Kreitler and Senger and modified by [9]. It gives the relation between the transfer time $t$ taken by a given substance in the groundwater to reach the borehole after the horizontal course of a distance $r$. The relation is as follows:

$$
t_{x}=\frac{n}{K i}\left[r_{x}-\left(\frac{Q}{2 \pi K b i}\right) \ln \left\{1+\left(\frac{2 \pi K b i}{Q}\right) r_{x}\right\}\right]
$$

with:

- $t_{x}$ : transfer time (day);

- $n$ : porosity of the aquifer;

- $K$ : hydraulic conductivity $(\mathrm{m} / \mathrm{d})$;

- Q. pumping rate $(\mathrm{m} 3 / \mathrm{j})$;

- $b$ : aquifer thickness (m);

- $i$ : hydraulic gradient;

- $r_{x}$ : radius (in meters) delimiting a surface following the isochron of transfer timetx. It is also the distance that the groundwater travels during the time interval $t$ before reaching the borehole.

To calculate such a distance as a function of time, we will have to write $r$ as a function of $t, n, K, Q, b$ and $i$.

The previous relation has been simplified by [9]. Simplification gives:

$$
t=A\left[r-\left(\frac{1}{F}\right) \ln (1+F \cdot r)\right]
$$

with $A=\frac{n}{K i}$ et $F=\frac{2 \pi K b i}{Q}$

The formula above giving $t$ can also be written in the following way:

$$
\frac{F \cdot t}{A}=F \cdot r-\ln n(1+F \cdot r)
$$

To determine the radius $r$, let's write $y=F \cdot r$ 
We obtain:

$$
\frac{F \cdot t}{A}=y-\ln (1+y)
$$

By writing $z=\frac{F \cdot t}{A}$, we have :

$$
z=y-\ln (1+y)
$$

This method neglects vertical flow and considers only regional horizontal flow to the catchment structure. PPRs and PPEs take the form of an ellipse characterized by three protective distances [10]:

- The protection distance in the upstream part of the structure or upstream radius $\left(r_{\text {amont }}\right)$;

- The protection distance in the downstream part of the structure or downstream radius $\left(r_{\text {aval }}\right)$;

- The protective distance perpendicular to the direction of flow $\left(r_{p}\right)$.

To determine different distances considered in the method as a function of time, Krijgsman and Lobo-Ferreira resulted in the following analytical relationships:

$$
\begin{gathered}
r_{\text {amont }}=\frac{0.00002 x^{5}-0.0009 x^{4}+0.015 x^{3}+0.37 x^{2}+x}{F} \\
r_{\text {aval }}=\frac{0.042 x^{3}+0.37 x^{2}+1.04 x}{F} \\
r_{p}=\sqrt{\frac{Q \cdot t}{\pi \cdot n \cdot b}}
\end{gathered}
$$

with:

$$
x=\sqrt{\frac{2 F \cdot t}{A}}=2 K i \sqrt{\frac{\pi \cdot b \cdot t}{Q \cdot n}} \text { and } F=\frac{2 \pi K \cdot b \cdot i}{Q} .
$$

The above $r_{\text {amont }}, r_{\text {aval }}$ and $r_{p}$ relations will be used to determine the PDP radii by the Krijgsman and Lobo-Ferreira method.

\section{Results}

\subsection{Delimitation of Protection Zones around the Boreholes of Ouedo}

\subsubsection{Determination of PDP Radii by the CFR Method}

The radii of the protection perimeters determined from the calculated fixed radius (CFR) method are presented in Table 1.

The distances of these radii vary between:

* $55.653 \mathrm{~m}$ and $99.755 \mathrm{~m}$ for a transfer time of 50 days;

* 212,575 m and 381,164 m for a transfer time of 2 years;

- 336,111 m and 602,672 $\mathrm{m}$ for a transfer time of 5 years.

This method allows us to assign the radii obtained to the different types of protection perimeters. 
Table 1. Determination of radii by the CFR method for different transfer times (50 days, 2 years and 5 years).

\begin{tabular}{|c|c|c|c|c|c|c|c|}
\hline \multirow{2}{*}{$\mathrm{N}^{\circ}$ Borehole } & \multirow{2}{*}{$\mathrm{N}^{\circ}$ Drillinge } & \multirow{2}{*}{$\begin{array}{l}\text { Exploitation } \\
\text { Flow } Q\left(\mathrm{~m}^{3} / \mathrm{h}\right)\end{array}$} & \multirow{2}{*}{ Porosity $n$} & \multirow{2}{*}{$\begin{array}{c}\text { Thickness of } \\
\text { the saturated } \\
\text { layer } H \text { ou } b \\
(\mathrm{~m})\end{array}$} & \multicolumn{3}{|c|}{$\begin{array}{l}\text { Calculated radii }(\mathrm{m}) \text { for different } \\
\text { transfer times } t\end{array}$} \\
\hline & & & & & $t=50$ days & $t=2$ years & $t=5$ years \\
\hline FO 1 & SEN 151 & 200 & 0.375 & 32.43 & 79.258 & 302.843 & 478.837 \\
\hline $\mathrm{FO} 2$ & SEN 159 & 200 & 0.375 & 35.47 & 75.785 & 289.575 & 457.858 \\
\hline FO 3 & SEN 162 & 140 & 0.375 & 32.59 & 66.149 & 252.754 & 399.639 \\
\hline FO 4 & SEN 165 & 140 & 0.375 & 29.54 & 69.480 & 265.482 & 419.764 \\
\hline FO 5 & SEN 22 & 200 & 0.375 & 32.39 & 79.307 & 303.030 & 479.133 \\
\hline FO 6 & SEN 19 & 200 & 0.375 & 35.4 & 75.860 & 289.861 & 458.311 \\
\hline FO 7 & SEN 14 & 120 & 0.375 & 23.62 & 71.937 & 274.870 & 434.607 \\
\hline FO 8 & SEN 05 & 200 & 0.375 & 26.57 & 87.563 & 334.577 & 529.012 \\
\hline FO 9 & SEN 17 & 140 & 0.375 & 23.64 & 77.668 & 296.768 & 469.231 \\
\hline FO 10 & SEN 09 & 140 & 0.375 & 29.68 & 69.316 & 264.855 & 418.773 \\
\hline FO 11 & SEN 27 & 250 & 0.375 & 25.59 & 99.755 & 381.164 & 602.672 \\
\hline FO 12 & SEN 68 & 100 & 0.375 & 23.66 & 65.613 & 250.709 & 396.405 \\
\hline FO 13 & SEN 47 & 100 & 0.375 & 32.91 & 55.633 & 212.575 & 336.111 \\
\hline FO 14 & SEN 41 & 100 & 0.375 & 29.59 & 58.672 & 224.184 & 354.466 \\
\hline FO 15 & SEN 34 & 250 & 0.375 & 35.38 & 84.838 & 324.166 & 512.552 \\
\hline FO 16 & SEN 31 & 200 & 0.375 & 32.22 & 79.516 & 303.829 & 480.395 \\
\hline
\end{tabular}

Indeed:

$\checkmark$ Rays obtained for a transfer time of 50 days will be allocated to immediate protection areas;

$\checkmark$ Rays obtained for a transfer time of 2 years will be allocated to the close protection areas:

$\checkmark$ Rays obtained for a transfer time of 5 years will be allocated to the remote protection perimeters.

It should be noted that according to the method, no industrial plant is permitted at a distance of less than 500 meters from the catchments.

\subsubsection{Determination of PDP Radii by the Infiltration Method}

Using the infiltration method, we obtain the values shown in Table 2.

The rays obtained by this method vary between 827,713 meters and 1308,730 meters. These rays obtained by the method of infiltration are even larger than the rays obtained by method CFR for the remote protection perimeters. In this case thus, the rays obtained will be allocated to the remote protection perimeters.

\subsubsection{Determination of PDP Radii by the Krijgsman and Lobo-Ferreira Method}

The Krijgsman and Lobo-Ferreira method allowed us to determine the three types of rays: the upstream ray, the downstream ray and the radius perpendicular 
Table 2. Determination of the rays by the infiltration method.

\begin{tabular}{lcccc}
\hline & N Drilling & $\begin{array}{c}\text { Exploitation Flow } \\
Q\left(\mathrm{~m}^{3} / \mathrm{h}\right)\end{array}$ & $\begin{array}{c}\text { Annual Refill } W \\
\left(\mathrm{~m}^{3} / \mathrm{an}\right)\end{array}$ & Radius $R(\mathrm{~m})$ \\
\hline FO 1 & SEN 151 & 200 & 0.407 & 1170.563 \\
FO 2 & SEN 159 & 200 & 0.407 & 1170.563 \\
FO 3 & SEN 162 & 140 & 0.407 & $\mathbf{9 7 9 . 3 6 4}$ \\
FO 4 & SEN 165 & 140 & 0.407 & $\mathbf{9 7 9 . 3 6 4}$ \\
FO 5 & SEN 22 & 200 & 0.407 & $\mathbf{1 1 7 0 . 5 6 3}$ \\
FO 6 & SEN 19 & 200 & 0.407 & $\mathbf{1 1 7 0 . 5 6 3}$ \\
FO 7 & SEN 14 & 120 & 0.407 & $\mathbf{9 0 6 . 7 1 4}$ \\
FO 8 & SEN 05 & 200 & 0.407 & $\mathbf{1 1 7 0 . 5 6 3}$ \\
FO 9 & SEN 17 & 140 & 0.407 & $\mathbf{9 7 9 . 3 6 4}$ \\
FO 10 & SEN 09 & 140 & 0.407 & $\mathbf{9 7 9 . 3 6 4}$ \\
FO 11 & SEN 27 & 250 & 0.407 & $\mathbf{1 3 0 8 . 7 3 0}$ \\
FO 12 & SEN 68 & 100 & 0.407 & $\mathbf{8 2 7 . 7 1 3}$ \\
FO 13 & SEN 47 & 100 & 0.407 & $\mathbf{8 2 7 . 7 1 3}$ \\
FO 14 & SEN 41 & 100 & 0.407 & $\mathbf{8 2 7 . 7 1 3}$ \\
FO 15 & SEN 34 & 250 & 0.407 & $\mathbf{1 3 0 8 . 7 3 0}$ \\
FO 16 & SEN 31 & 200 & 0.407 & $\mathbf{1 1 7 0 . 5 6 3}$ \\
\hline
\end{tabular}

to the direction of flow at right angles to the borehole. Before determining the radii of the protection perimeters using this method, we first had to determine the hydraulic gradient through the exploitation of the piezometric map which we have carried out and which takes into account the sector d'study.

The piezometric map of the area covering the study area was obtained using the Arc-GIS 9.3 software on the basis of the GPS data and the various measurements (static level and curb height) carried out in the field. Figure 2 shows the superimposition of wells and isopies (isopiezometric curves) on the background of the study area map showing rivers, water bodies and wetland or marshy areas.

From this map, we determined the hydraulic gradient which is about $0.165 \%$.The radii for $t=50$ days of the determined protection perimeters using the Krijgsman and Lobo-Ferreira methods are presented in Table 3.

The radii for $t=2$ years days of the determined protection perimeters using the Krijgsman and Lobo-Ferreira methods are presented in Table 4.

The radii for $t=5$ years days of the determined protection perimeters using the Krijgsman and Lobo-Ferreira methods are presented in Table 5.

The PDPs being calculated for different transfer times, we will retain that:

- PPIs are those whose radii have been calculated for a transfer time of 50 days;

- PPRs are those whose radii have been calculated for a transfer time of 2 years;

- PPEs are those whose radii have been calculated for a transfer time of 5 years.

Analysis of these tables reveals that: 


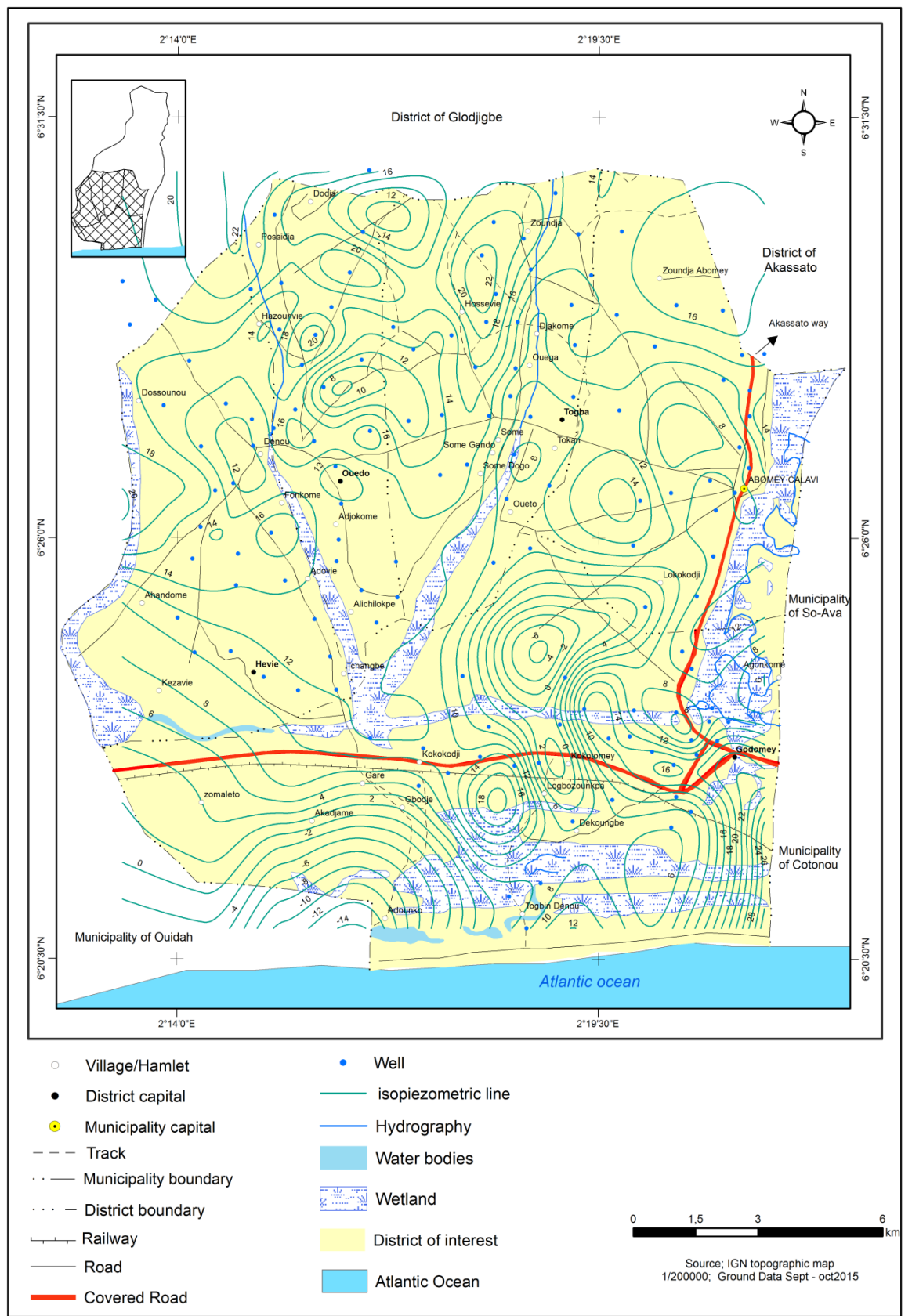

Figure 2. Piezometric map of the area covering the study zone [11].

$\checkmark$ Rays upstream of boreholes vary between $56.19 \mathrm{~m}$ and $100.39 \mathrm{~m}$ for PPIs, between $220.72 \mathrm{~m}$ and $390 \mathrm{~m}$ for PPR and between $356.52 \mathrm{~m}$ and $659.52 \mathrm{~m}$ for PPE;

$\checkmark$ Rays downstream of boreholes vary between $57.30 \mathrm{~m}$ and $103.11 \mathrm{~m}$ for PPI, between $213.06 \mathrm{~m}$ and $387.25 \mathrm{~m}$ for PPR and between $321.28 \mathrm{~m}$ and $603.97 \mathrm{~m}$ for PPE:

$\checkmark$ The radii perpendicular to the direction of flow at each drill borehole range from $55.63 \mathrm{~m}$ to $99.76 \mathrm{~m}$ for the PPI, from $212.58 \mathrm{~m}$ to $381.16 \mathrm{~m}$ for the PPR and from $336.11 \mathrm{~m}$ And $602.67 \mathrm{~m}$ for PPE. 
Table 3. Determination of rays for a transfer time of 50 days.

\begin{tabular}{cccccc}
\hline \multirow{2}{*}{$\mathrm{N}^{\circ}$ Borehole } & \multirow{2}{*}{$F$} & \multirow{3}{c}{ Radii for $t=50$ days } \\
\cline { 4 - 6 } & & & $R_{a m}(\mathrm{~m})$ & $R_{a v}(\mathrm{~m})$ & $R_{\mathrm{p}}(\mathrm{m})$ \\
\hline FO 1 & 0.00205272 & 0.16269364 & $\mathbf{8 4 . 0 6}$ & $\mathbf{7 7 . 7 5}$ & $\mathbf{7 9 . 2 6}$ \\
FO 2 & 0.00138092 & 0.10465320 & $\mathbf{7 8 . 7 3}$ & 75.92 & 75.79 \\
FO 3 & 0.00173281 & 0.11462346 & $\mathbf{6 8 . 9 7}$ & $\mathbf{6 6 . 0 3}$ & $\mathbf{6 6 . 1 5}$ \\
FO 4 & 0.00189276 & 0.13150899 & $\mathbf{7 2 . 8 8}$ & $\mathbf{6 8 . 9 3}$ & $\mathbf{6 9 . 4 8}$ \\
FO 5 & 0.00113832 & 0.09027671 & $\mathbf{8 1 . 9 7}$ & $\mathbf{7 9 . 8 6}$ & $\mathbf{7 9 . 3 1}$ \\
FO 6 & 0.00134360 & 0.10192536 & $\mathbf{7 8 . 7 3}$ & $\mathbf{7 6 . 0 7}$ & $\mathbf{7 5 . 8 6}$ \\
FO 7 & 0.00130627 & 0.09396910 & $\mathbf{7 4 . 4 5}$ & $\mathbf{7 2 . 3 4}$ & $\mathbf{7 1 . 9 4}$ \\
FO 8 & 0.00087707 & 0.07679863 & $\mathbf{9 0 . 0 6}$ & $\mathbf{8 8 . 6 0}$ & $\mathbf{8 7 . 5 6}$ \\
FO 9 & 0.00053317 & 0.04141032 & $\mathbf{7 8 . 8 6}$ & $\mathbf{7 9 . 5 9}$ & $\mathbf{7 7 . 6 7}$ \\
FO 10 & 0.00063981 & 0.04434878 & $\mathbf{7 0 . 4 6}$ & $\mathbf{7 0 . 9 6}$ & $\mathbf{6 9 . 3 2}$ \\
FO 11 & 0.00017175 & 0.01713261 & $\mathbf{1 0 0 . 3 9}$ & $\mathbf{1 0 3 . 1 1}$ & $\mathbf{9 9 . 7 6}$ \\
FO 12 & 0.00126895 & 0.08326029 & $\mathbf{6 7 . 6 4}$ & $\mathbf{6 6 . 2 4}$ & $\mathbf{6 5 . 6 1}$ \\
FO 13 & 0.00048519 & 0.02699267 & $\mathbf{5 6 . 1 9}$ & $\mathbf{5 7 . 3 0}$ & $\mathbf{5 5 . 6 3}$ \\
FO 14 & 0.00048519 & 0.02846671 & $\mathbf{5 9 . 2 9}$ & $\mathbf{6 0 . 4 0}$ & $\mathbf{5 8 . 6 7}$ \\
FO 15 & 0.00062701 & 0.05319450 & $\mathbf{8 6 . 5 1}$ & $\mathbf{8 6 . 5 7}$ & $\mathbf{8 4 . 8 4}$ \\
FO 16 & 0.00087707 & 0.06974073 & $\mathbf{8 1 . 5 7}$ & $\mathbf{8 0 . 6 6}$ & $\mathbf{7 9 . 5 2}$ \\
\hline
\end{tabular}

Table 4. Determination of radii for a transfer time of 2 years (730 days).

\begin{tabular}{|c|c|c|c|c|c|}
\hline \multirow{2}{*}{$\mathrm{N}^{\circ}$ Borehole } & \multirow{2}{*}{$F$} & \multirow{2}{*}{$x$} & \multicolumn{3}{|c|}{ Radii for $t=2$ years } \\
\hline & & & $R_{a m}(\mathrm{~m})$ & $R_{a v}(\mathrm{~m})$ & $R_{p}(\mathrm{~m})$ \\
\hline FO 1 & 0.00205272 & 0.62165153 & 374.19 & 250.22 & 302.84 \\
\hline FO 2 & 0.00138092 & 0.39987930 & 333.10 & 260.26 & 289.57 \\
\hline FO 3 & 0.00173281 & 0.43797564 & 294.42 & 223.94 & 252.75 \\
\hline FO 4 & 0.00189276 & 0.50249516 & 315.82 & 229.56 & 265.48 \\
\hline FO 5 & 0.00113832 & 0.34494683 & 342.24 & 277.99 & 303.03 \\
\hline FO 6 & 0.00134360 & 0.38945624 & 332.27 & 261.53 & 289.86 \\
\hline FO 7 & 0.00130627 & 0.35905544 & 311.91 & 250.84 & 274.87 \\
\hline FO 8 & 0.00087707 & 0.29344714 & 371.33 & 312.84 & 334.58 \\
\hline FO 9 & 0.00053317 & 0.15822862 & 314.25 & 291.58 & 296.77 \\
\hline FO 10 & 0.00063981 & 0.16945644 & 281.57 & 259.16 & 264.86 \\
\hline FO 11 & 0.00017175 & 0.06546361 & 390.42 & 387.25 & 381.16 \\
\hline FO 12 & 0.00126895 & 0.31813712 & 280.59 & 232.29 & 250.71 \\
\hline FO 13 & 0.00048519 & 0.10313883 & 220.72 & 213.06 & 212.58 \\
\hline FO 14 & 0.00048519 & 0.10877114 & 233.25 & 224.24 & 224.18 \\
\hline FO 15 & 0.00062701 & 0.20325590 & 348.74 & 313.32 & 324.17 \\
\hline FO 16 & 0.00087707 & 0.26647894 & 334.10 & 286.93 & 303.83 \\
\hline
\end{tabular}


Table 5. Determination of radii for a transfer time of 5 years (1825 days).

\begin{tabular}{|c|c|c|c|c|c|}
\hline \multirow{2}{*}{$\mathrm{N}^{\circ}$ Borehole } & \multirow{2}{*}{$F$} & \multirow{2}{*}{$x$} & \multicolumn{3}{|c|}{ Radii for $t=5$ years } \\
\hline & & & $R_{a m}(\mathrm{~m})$ & $R_{a v}(\mathrm{~m})$ & $R_{p}(\mathrm{~m})$ \\
\hline FO 1 & 0.00205272 & 0.98291737 & 659.52 & 343.28 & 478.84 \\
\hline FO 2 & 0.00138092 & 0.63226469 & 567.61 & 376.75 & 457.86 \\
\hline FO 3 & 0.00173281 & 0.69250029 & 504.79 & 321.28 & 399.64 \\
\hline FO 4 & 0.00189276 & 0.79451460 & 546.95 & 324.29 & 419.76 \\
\hline FO 5 & 0.00113832 & 0.54540883 & 577.89 & 407.59 & 479.13 \\
\hline FO 6 & 0.00134360 & 0.61578438 & 565.24 & 379.52 & 458.31 \\
\hline FO 7 & 0.00130627 & 0.56771650 & 527.93 & 366.58 & 434.61 \\
\hline FO 8 & 0.00087707 & 0.46398066 & 621.49 & 464.14 & 529.01 \\
\hline FO 9 & 0.00053317 & 0.25018141 & 513.10 & 445.80 & 469.23 \\
\hline FO 10 & 0.00063981 & 0.26793415 & 460.73 & 395.27 & 418.77 \\
\hline FO 11 & 0.00017175 & 0.10350705 & 625.85 & 603.97 & 602.67 \\
\hline FO 12 & 0.00126895 & 0.50301895 & 471.64 & 342.70 & 396.40 \\
\hline FO 13 & 0.00048519 & 0.16307681 & 356.52 & 329.65 & 336.11 \\
\hline FO 14 & 0.00048519 & 0.17198227 & 377.18 & 346.53 & 354.47 \\
\hline FO 15 & 0.00062701 & 0.32137580 & 574.28 & 474.33 & 512.55 \\
\hline FO 16 & 0.00087707 & 0.42134019 & 556.53 & 428.30 & 480.40 \\
\hline
\end{tabular}

\subsection{Representation of Protection Perimeters}

In the present work only the PDPs obtained by the calculated fixed radius method and the infiltration method were represented. These representations were made with the software Arc-GIS 9.3. All the PPIs of the Ouedo catchment area measure approximately $7516.88 \mathrm{~m}$ with an area of $286,719.12 \mathrm{~m}^{2}$; All the PPRs of the catchment area of Ouedo measure approximately $18,789.91 \mathrm{~m}$ with an area of 3,567,370.06 $\mathrm{m}^{2}$; The total of the PPEs of the catchment area of Ouedo is approximately $18,204.22 \mathrm{~m}$ with an area of $6,753,204.48 \mathrm{~m}^{2}$.

The PPE obtained have an overall perimeter of 22,474.58 m with an area of approximately $20,115,759.76 \mathrm{~m}^{2}$ or $20.12 \mathrm{~km}^{2}$. The calculations show that the area of PPE obtained by the infiltration method is close to three times the area of PPE obtained by the CFR method. Figure 3 gives a view of the superposition of the PDPs on the land-use plan of the drilling site of the drilling field of the Ouedo catchment field.

\section{Discussion}

The realization of the piezometric map for the determination of the protection perimeters (PDP) allowed us to have more precision on the values of these PDP. Indeed, using this piezometric map, we obtained a hydraulic gradient covering only the sector encompassing the catchment areas of Godomey and Ouedo. The obtained value of this hydraulic gradient, equal to $0.165 \%$, differs widely from 


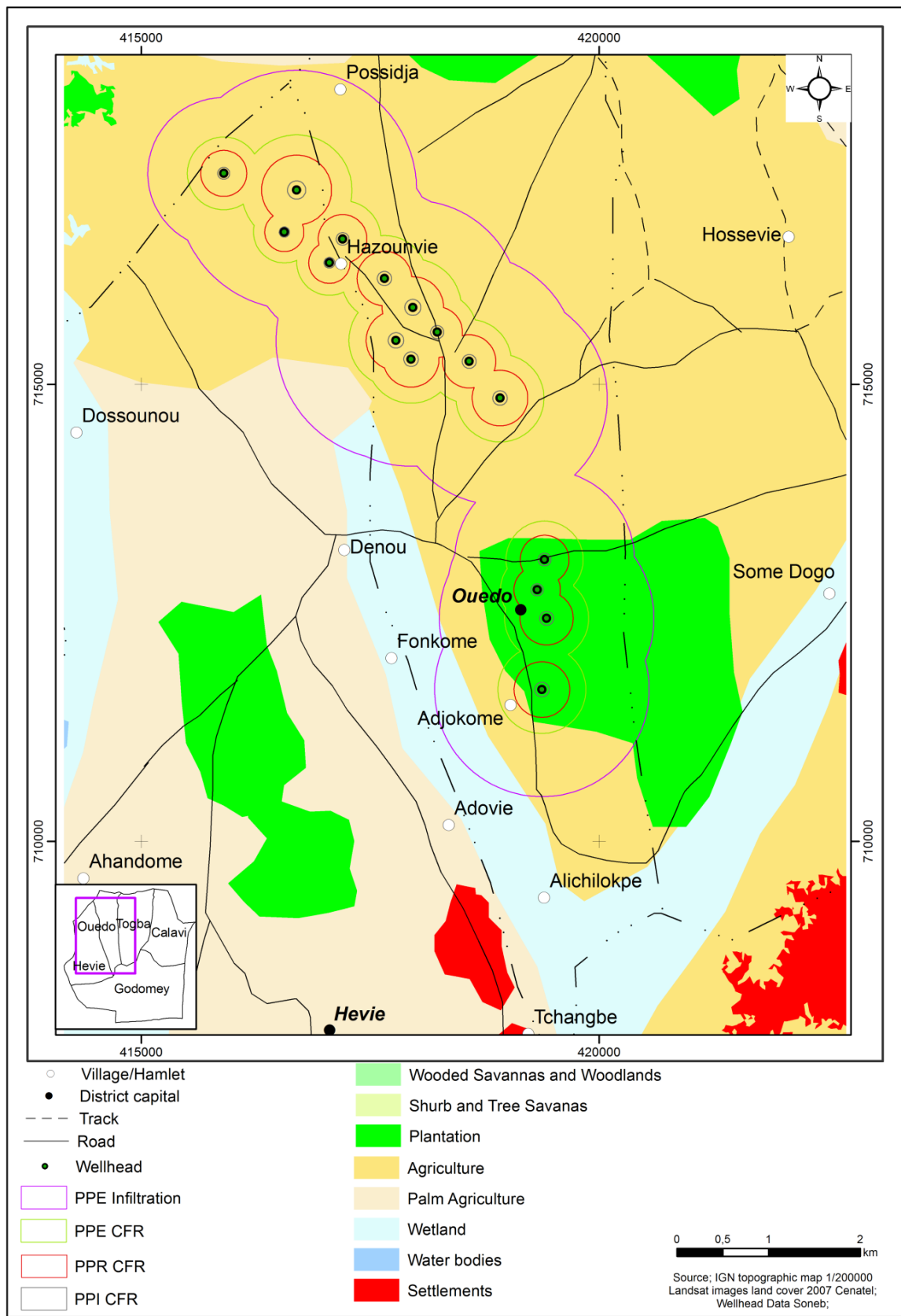

Figure 3. Location of PDPs on Soil Occupancy [11].

that used by [12], equal to $2.5 \%$ for PDP determination in the same study area. The value of the hydraulic gradient is used for the calculation of PDP radii in the Krijgsman and Lobo-Ferreira method. Thus, the results obtained for this method in the present work differ from the results obtained by [12].

The PPI values obtained by the CFR method range from $349.56 \mathrm{~m}$ to $626.78 \mathrm{~m}$ while the PPI values obtained by the Krijgsman and Lobo-Ferreira method range from $353.06 \mathrm{~m}$ to $633.07 \mathrm{~m}$. Moreover, the values of the areas of the PPIs obtained by the CFR method vary from $9723.49 \mathrm{~m}^{2}$ to $31,262.21 \mathrm{~m}^{2}$ while the values of the PPI areas obtained by the Krijgsman and Lobo-Ferreira method vary 
from $9918.16 \mathrm{~m}^{2}$ to $31,887.72 \mathrm{~m}^{2}$. The analysis of the results obtained shows that the PPI values obtained for these two methods are relatively close with a maximum deviation of $6.29 \mathrm{~m}$. On the other hand, the values of the areas of the PPI obtained for these two methods are more or less remote with a maximum difference of $625.51 \mathrm{~m}^{2}$. Since the PPIs should be as small as possible while ensuring effective protection of the catchments, the method of determining these perimeters will then be applied to the CFR method. However, the radius values of the PPI obtained by the CFR method are higher than the value required in countries such as France, Germany and Switzerland (between $10 \mathrm{~m}$ and $20 \mathrm{~m}$ ) as well as in the United States $(30 \mathrm{~m})$. In the field, the immediate protective perimeters already in place have values of $15 \mathrm{~m} \times 20 \mathrm{~m}$. Previous studies carried out by the General Office of Water (DGEau) [13] make it possible to provide a minimum radius of $100 \mathrm{~m}$ for PPR. By comparing the PPR rays obtained by the two methods (CFR and the Krijgsman and Lobo-Ferreira method) in this document, we note that the PPR rays obtained by the Krijgsman and Lobo-Ferreira method are relatively larger than those obtained by the CFR method. However, the radii of the PPRs obtained from the Krijgsman and Lobo-Ferreira methods are those that are best suited mainly because of the inclusion of the hydraulic gradient. It is the taking into account of this hydraulic gradient which gives them the ellipsoidal shape. For the PDP determination, the Krijgsman and Lobo Ferreira method is one of the three methods used in this study, which takes more account of the intrinsic characteristics of the environment. It takes into account the regional underground flow that is at the base of the hydraulic gradient and incorporates more hydrodynamic parameters of the captured aquifer. It will then be preferred to determine the radii of the PPE, in contrast to the infiltration method that does not take into account the hydrodynamic characteristics of the aquifer or the transfer time.

\section{Conclusion}

The determination of the radii of the immediate, close and remote protection areas around the Ouedo field catchments was based on the simultaneous use of calculated computed radius (CFR), infiltration refill and Krijgsman methods, and Lobo-Ferreira. We produced a piezometric map covering the sector encompassing the Ouedo and Godomey fields in order to obtain a more precise value of the hydraulic gradient of this sector. It is this gradient obtained that allowed us to perform our calculations with the method of Krijgsman and Lobo-Ferreira. The radii of the PPIs selected in this study are those obtained by the CFR method and range from $55.653 \mathrm{~m}$ to $99.755 \mathrm{~m}$. The rays of the PPRs and of the PPEs selected are those obtained by the analytical method of Krijgsman and Lobo-Ferreira. These PPRs and PPEs have an ellipsoidal shape due to the hydraulic gradient of the underground flow of the aquifer taken into account. The determined upstream radii vary from $220.72 \mathrm{~m}$ to $390 \mathrm{~m}$ for the PPR and from 356.52 $\mathrm{m}$ to $659.52 \mathrm{~m}$ for the PPE; Downstream radii range from $213.06 \mathrm{~m}$ to $387.25 \mathrm{~m}$ 
for PPR and from $321.28 \mathrm{~m}$ to $603.97 \mathrm{~m}$ for PPE; The radii perpendicular to the direction of flow at each drill hole range from $212.58 \mathrm{~m}$ to $381.16 \mathrm{~m}$ for the PPR and from 336.11 to $602.67 \mathrm{~m}$ for the PPE. The probable risks of contamination of identified groundwater in these protection areas are the discharge of domestic sewage from septic tanks, the dumping of solid waste into lost wells and the use of chemical fertilizers and pesticides used in agricultural practices. Industrial pollution is excluded because there are no industrial production units around the boreholes. It would be interesting for other methods to be used for the determination of PDPs in order to compare the results obtained and thus obtain more accurate results. Finally, chemical studies should also be carried out in the laboratory on various types of pollutants to determine the mode of transport of these pollutants and estimate the time from which they would no longer pose a danger to human food.

\section{References}

[1] Rasmussen, H., Rouleau, A. and Chevalier, S. (2006) Tools for Determining Feeding and Protection Areas of Groundwater Catchments. 2nd Edition, 303 p.

[2] Kouame, K., Jourda, J., Deh, S.K., Djemin, E.J., Mahaman Bachir, S., Anani, A.T. and Biemi, J. (2014) Contribution of Mathematical Methods in the Delimitation of the Protection Perimeters around the Abidjan Groundwater Borehole (Côte d'Ivoire). International Journal of Biological and Chemical Sciences, 7. https://doi.org/10.4314/ijbcs.v7i5.17

[3] Afrique Conseil (2006) Monography of Abomey-Calavi. 72 p.

[4] Struckmeier, W.F. and Margat, J. (1995) Hydrogeological Map. A Guide and a Standard Legend. International Association of Hydrogeologists.

[5] French, H.K., Van, S.M. and Leijnse, A. (2000) Prediction Uncertainty of Plume Characteristics Derived from a Small Number of Measuring Points. Hydrogeology Journal, 8, 188-199. https://doi.org/10.1007/s100400050005

[6] Hudak, P.F. (2000) Procedure for Upgrading Contaminant Detection Networks in Aquifers. Bulletin of Environment and Contaminant Toxicology, 65, 62-69. https://doi.org/10.1007/s0012800095

[7] Kresic, N. (2007) Hydrogeology and Groundwater Modeling. 2nd Edition, 450 p.

[8] Kruseman, G.P. and De Ridder, N.A. (1990) Analysis and Evaluation of Pumping Test Data. International Institute for Land Reclamation and Improvement. Wageningen, 2nd Edition, $376 \mathrm{p}$.

[9] Bear, J. and Jacobs, M. (1965) On the Movement of Water Bodies Injected into Aquifer. Journal of Hydrology, 3, 37-57. https://doi.org/10.1016/0022-1694(65)90065-X

[10] Verreault, M. (2003) Methodological Study for Estimation of the Alimentation Captage Area of Groundwater in the Complexe Environment. Matersmemoire of Chicoutimi University of Québec, Translated from French, Chicoutimi, $131 \mathrm{p}$.

[11] Joanele, K.Z. (2015) Piezometry of the Aquifer of the Continental Terminal in the Borehole Fields of Godomey and Ouedo for the Delimitation of the Protection Areas around Boreholes of Ouedo. Maters mémoire, EPAC/UAC, 141 p.

[12] Djaboutou (2014) Contribution of the Analytical Methods in the Delimitation of the Perimeters of Protection around the Boreholes: Application to the Well Field of 
Ouedo, Translate from French, Engeneering Dissertation, EPAC/UAC, 141 p.

[13] DGEau (2010) Implementation of a Protection System for Drinking Water Catchment Areas: A Methodological Guide for Municipalities in the Republic of Benin, Translate from French, $32 \mathrm{p}$. 